\title{
Pediatrician's role in vaccinating children and families for COVID-19: no one left behind
}

\author{
Annabelle de St. Maurice ${ }^{1}$, Tina L. Cheng ${ }^{2}$, Sherin U. Devaskar ${ }^{2}{ }^{凶}$ and on behalf of the Pediatric Policy Council* \\ (c) The Author(s) 2021
}

Pediatric Research (2021) 90:1105-1107; https://doi.org/10.1038/s41390-021-01804-z

The importance of coronavirus disease 2019 (COVID-19) vaccines in children has been debated during the pandemic because the incidence of COVID-19 in children is lower than in adults, with particularly low rates in children $<5$ years of age. ${ }^{1}$ However, the physical and mental health of children has been greatly impacted by both direct and indirect effects of the COVID-19 pandemic. More than six million children have been diagnosed with COVID-19 in the United States alone ${ }^{1}$, over 4,000 children have been hospitalized ${ }^{2}$ and over 600 children have died. ${ }^{1}$ Globally, there have been over ten million COVID-19 cases and over 4000 deaths in persons 19 years of age and younger. ${ }^{3}$ The number of pediatric COVID-19 cases may be underestimated because children tend to have milder symptoms from infection and may be less likely to be tested than adults, particularly in low- and middle-income countries where access to testing may be limited. and COVID-19 case data are not always reported by age group. Children infected with severe acute respiratory syndrome coronavirus 2 (SARS-CoV-2) are at risk of postinfectious complications including Multi-system Inflammatory Syndrome in Children ${ }^{4}$ and "long-COVID." ${ }^{5}$ Pandemic mitigation measures such as school closures and cancellation of athletic activities have been associated with increased mental health difficulties and obesity rates in children, and have widened health disparities related to race/ethnicity and socioeconomic status. ${ }^{6}$ Beyond COVID-19 infection, the impact of the pandemic on children's mental and physical wellbeing and educational progress has been far-reaching. ${ }^{7}$

More recently, the emergence of the more transmissible Delta variant has magnified the threat to children globally. The proportion of new COVID-19 cases in children has increased substantially from May through November 2021. ${ }^{3}$ During the week of November 11 2021, children accounted for over 120,000 new COVID-19 cases in the United States and represented 27\% of the weekly COVID-19 cases. $^{8}$ Until a greater proportion of the overall global population is vaccinated, new variants will continue to emerge.

For these reasons and more, it is important for all children aged 6 months to 17 years of age to be vaccinated against COVID-19 when vaccine efficacy and safety data are available and rigorously evaluated. Children constitute over $30 \%$ of the world's population, ${ }^{9}$ yet are largely unvaccinated against COVID-19, because until recently the vaccine had not been approved for children $<12$ years of age. Childhood vaccinations have lagged primarily because COVID-19 vaccines were first studied in adults, given the higher incidence and severity of illness in the older population. In the United States, the only vaccine to have received emergency use authorization for children as young as 5 years of age is the PfizerBioNTech vaccine ${ }^{10,11}$ and several vaccine manufacturers are studying COVID-19 vaccines in children as young as 6 months of age. Fortunately, pediatric COVID-19 vaccinations have been found to be safe and effective for children 5 years of age and older, ${ }^{12-14}$ with the benefits far outweighing risks.

In addition, children play a role in COVID-19 transmission to other children and adults including the most vulnerable immunocompromised individuals. As Pratico and Ruggieri state in their article, unvaccinated children could potentially lead to transmission events in adults, similar to prior measles outbreaks. ${ }^{15}$ There are reports of infected children who have been vectors of transmission to their vaccinated or unvaccinated parents and this risk will likely increase as new variants arise and schools reopen. ${ }^{16}$ Although it is unlikely that COVID-19 will be eradicated given the high transmissibility of the virus and ability to mutate, vaccinating children can have a large impact on reducing transmission and severity of illness in children and adults while contributing to herd immunity. Pediatricians and other pediatric providers must play an active role in educating and providing vaccines to children as parents frequently cite their pediatric clinician as a trusted source of information regarding vaccines. ${ }^{17}$ Providing COVID-19 vaccines during well-child checks and sick visits may increase access to vaccines and ultimately increase vaccination rates in children. Pediatric practices are also an opportune location to offer vaccination to family members for multiple reasons, including: (1) infection transmission often occurs in families and vaccinating the entire family protects everyone; (2) pediatric clinicians are experts in discussing vaccines and vaccine hesitancy and are trusted; and (3) family members accompany children to pediatric visits where vaccines are available. Many practices have offered this approach as an efficient and effective mechanism to increase education and access to vaccines in their community. This is important as we know that the health of children is interdependent on the health of the family and their community. Finally, there also exists the opportunity to partner with schools, other educational institutions, and Pediatric-focused organizations to advocate for vaccines while educating families on the importance of vaccinating children of all ages when the vaccines are authorized for such use.

Researchers should continue to enroll young children in clinical trials aimed at evaluating the safety and efficacy of these vaccines. Vaccines should not be given to very young children until the efficacy, safety, and dosing have been thoroughly

\footnotetext{
${ }^{1}$ Department of Pediatrics, David Geffen School of Medicine at UCLA, UCLA Mattel Children's Hospital, Los Angeles, CA, USA. ${ }^{2}$ Department of Pediatrics, Cincinnati Children's
} Hospital and University of Cincinnati, Cincinnati, OH, USA. ${ }^{*}$ A list of authors and their affiliations appears at the end of the paper. ${ }^{\circledR}$ email: Sdevaskar@mednet.ucla.edu

Received: 11 August 2021 Revised: 27 September 2021 Accepted: 10 October 2021

Published online: 24 November 2021 
studied and vaccine experts have provided recommendations for administration. ${ }^{18}$ Potential rare adverse events, such as myocarditis, ${ }^{19}$ should continue to be investigated thoroughly. The background rate of myocarditis in individuals in the United States is estimated to be 1 to 10 per 100,000 persons annually with variations by age group and gender ${ }^{20}$ and the risk increases after SARS-CoV-2 infection. The rate of myocarditis after SARSCoV-2 infection is estimated to be 6-34 times greater than the risk of messenger RNA vaccine-associated myocarditis and vaccine experts largely agree that the benefits of vaccination far outweigh the risk of myocarditis in children age 12 years and above. $^{21,22}$ Similar risk-benefit analyses should be conducted on children who are younger than 12 years of age and maybe at lower risk of severe COVID-19 infection.

Global organizations including the World Health Organization and COVAX should work with vaccine manufacturers to expeditiously facilitate vaccine trials in children globally. Emergency-use authorization and licensure of these vaccines globally should be held to the same standards as adult vaccines. In addition to children, it is essential that future clinical trials include pregnant and lactating mothers to establish safety and efficacy in this vulnerable population (also protecting the fetus and other children). High-risk conditions such as preterm labor and preeclampsia-like features have emerged in mothers infected with SARS-CoV-2 and their infants have suffered the consequences of prematurity and fetal inflammatory response syndrome. ${ }^{23}$ Since more data have emerged demonstrating the safety and efficacy of these vaccines in pregnant and lactating women, pediatric organizations should support the Society for Maternal Fetal Medicine and $\mathrm{ACOG}^{18}$ in encouraging all pregnant and lactating women to receive a COVID-19 vaccination. Pediatric practices should also consider providing COVID-19 vaccines to parents.

Access to pediatric vaccines must be equitable globally. Thus far, the disparities in vaccine distribution globally have been striking. High-income nations have vaccinated the majority of their population, including the United Arab Emirates, which has vaccinated $98 \%$ of their population. ${ }^{24}$ In contrast, low- and middle-income countries such as Haiti have yet to vaccinate $1 \%$ of their population. ${ }^{24}$ While some wealthy nations are providing supplemental and booster doses to their population, many healthcare workers in low-income countries have yet to receive a single vaccine dose. It is important for leaders of wealthy nations to improve vaccine equity outside their own borders. Administering the primary COVID-19 vaccine series to high-risk individuals in low- and middle-income countries should be a global priority and responsibility of all nations. Public health leaders should balance priorities in rolling out vaccines to low-risk children age $<5$ vs the possibility of a substantial impact on global vaccine availability.

If adults and children in any global community are left behind in COVID-19 vaccine programs, it will be more difficult to mitigate the spread of SARS-CoV-2 for all, and pediatric hospitalizations and deaths will continue to increase globally.

\section{REFERENCES}

1. Centers for Disease Control and Prevention. COVID data tracker. https://covid.cdc. gov/covid-data-tracker/\#demographics (2021).

2. Centers for Disease Control and Prevention, COVID-NET, Laboratory Confirmed COVID-19 Associated Hospitalizations, https://gis.cdc.gov/grasp/COVIDNet/ COVID19_3.html https://gis.cdc.gov/grasp/COVIDNet/COVID19_3.html, Accessed November 18, 2021.

3. World Health Organization. WHO COVID19 detailed surveillance dashboard. https:// app.powerbi.com/view?r=eyJrljoiYWRiZWVkNWUtNmMONi00MDAwLTljYWMtN2Ew NTM3YjQzYmRmliwidCI6ImY2MTBjMGI3LWJkMjQtNGIzOS04MTBiLTNkYz|4MGFmYjU5MClsImMiOjh9. Accessed November 18, 2021

4. Holm, M. et al. Multisystem inflammatory syndrome in children occurred in one of four thousand children with severe acute respiratory syndrome coronavirus 2 . Acta Paediatr. 110, 2581-2583 (2021).
5. Buonsenso, D. et al. Preliminary evidence on long COVID in children. Acta Paediatr. 110, 2208-2211 (2021).

6. Hawrilenko, M., Kroshus, E., Tandon, P. \& Christakis, D. The association between school closures and child mental health during COVID-19. JAMA Netw. Open. 4, e2124092 (2021).

7. Cheng, T. L., Moon, M. \& Artman, M., On behalf of the Pediatric Policy C. Shoring up the safety net for children in the COVID-19 pandemic. Pediatr. Res. 88, 349-351 (2020)

8. AAoP. Children and COVID-19: state-level data report. https://www.aap.org/en/ pages/2019-novel-coronavirus-covid-19-infections/children-and-covid-19-statelevel-data-report/ (2021). Accessed: November 18, 2021

9. United Nations. World population prospects. https://population.un.org/wpp/ DataQuery/ (2019).

10. Wallace, M. et al. The Advisory Committee on Immunization Practices' Interim Recommendation for Use of Pfizer-BioNTech COVID-19 Vaccine in Adolescents Aged 12-15 Years-United States, May 2021. Morb. Mortal. Wkly Rep. 70, 749-752 (2021).

11. Woodworth, K. R. et al. The Advisory Committee on Immunization Practices' Interim Recommendation for Use of Pfizer-BioNTech COVID-19 Vaccine in Children Aged 5-11 Years - United States, November 2021. MMWR Morb Mortal Wkly Rep. 70, 1579-1583. (2021). https://doi.org/10.15585/mmwr.mm7045e1external icon.

12. Han, B. et al. Safety, tolerability, and immunogenicity of an inactivated SARS-CoV2 vaccine (CoronaVac) in healthy children and adolescents: a double-blind, randomised, controlled, phase 1/2 clinical trial. Lancet Infect. Dis. S1473-3099(21) 00319-4 https://doi.org/10.1016/S1473-3099(21)00319-4 (2021). [published online ahead of print, 2021 Jun 28]

13. Frenck, R. W. et al. Safety, immunogenicity, and efficacy of the BNT162b2 Covid19 vaccine in adolescents. N. Engl. J. Med. 385, 239-250 (2021).

14. Walter, E. B. et al. Evaluation of the BNT162b2 Covid-19 Vaccine in Children 5 to 11 Years of Age. N. Engl. J. Med. https://doi.org/10.1056/NEJMoa2116298 (2021). [published online ahead of print, 2021 Nov 9].

15. Pratico, A. \& Ruggieri, M. COVID-19 vaccination for children: may be necessary for full eradication of the disease. Pediatr. Res. 1-2 https://doi.org/10.1038/s41390021-01643-y (2021). [published online ahead of print, 2021 Jul 12].

16. Goldstein, E., Lipsitch, M. \& Cevik, M. On the effect of age on the transmission of SARS-CoV-2 in households, schools, and the community. J. Infect. Dis. 223, 362-369 (2021).

17. Taylor, J. A. et al. The influence of provider behavior, parental characteristics, and a public policy initiative on the immunization status of children followed by private pediatricians: a study from pediatric research in office settings. Pediatrics 99, 209-215 (1997).

18. American Academy of Pediatrics. American Academy of Pediatrics cautions against off-label use of COVID-19 vaccines in children under 12. https://www.aap. org/en/news-room/news-releases/aap/2021/american-academy-of-pediatricscautions-against-off-label-use-of-covid-19-vaccines-in-children-under-12/. Accessed September 12, 2021.

19. Advisory Committee on Immunization Practices. COVID-19 VaST Work Group Report-May 17, 2021. https://www.cdc.gov/vaccines/acip/work-groups-vast/ report-2021-05-17.html (2021). Accessed November 18, 2021.

20. Gubernot, D. et al. U.S. Population-based background incidence rates of medical conditions for use in safety assessment of COVID-19 vaccines. Vaccine 39, 3666-3677 (2021).

21. Boehmer, T. K. et al. Association Between COVID-19 and Myocarditis Using Hospital-Based Administrative Data — United States, March 2020-January 2021 MMWR Morb Mortal Wkly Rep. 70, 1228-1232 (2021). https://doi.org/10.15585/ mmwr.mm7035e5externalicon.

22. Dionne, A. et al. Association of myocarditis with BNT162b2 messenger RNA COVID-19 vaccine in a case series of children. JAMA Cardiol. e213471 https://doi. org/10.1001/jamacardio.2021.3471 (2021). [published online ahead of print, 2021 Aug 10].

23. Society for Maternal Fetal Medicine. SMFM: provider considerations for engaging in COVID-19 vaccine counseling with pregnant and lactating patients. https://s3. amazonaws.com/cdn.smfm.org/media/3039/Provider_Considerations_for_ Engaging_in_COVID_Vaccination_Considerations_7-30-21_\%28final\%29_pdf. Accessed November 18, 2021.

24. Ritchie, H. et al. Coronavirus Pandemic (COVID-19). (2020) Published online at OurWorldlnData.org. Retrieved from: https://ourworldindata.org/coronavirus [Online Resource].

\section{AUTHOR CONTRIBUTIONS}

All authors contributed to the draft and gave approval for the final version to be published. 


\section{COMPETING INTERESTS}

The authors declare no competing interests.

\section{ADDITIONAL INFORMATION}

Correspondence and requests for materials should be addressed to Sherin $U$. Devaskar.

Reprints and permission information is available at http://www.nature.com/ reprints

Publisher's note Springer Nature remains neutral with regard to jurisdictional claims in published maps and institutional affiliations.
Open Access This article is licensed under a Creative Commons Attribution 4.0 International License, which permits use, sharing, adaptation, distribution and reproduction in any medium or format, as long as you give appropriate credit to the original author(s) and the source, provide a link to the Creative Commons license, and indicate if changes were made. The images or other third party material in this article are included in the article's Creative Commons license, unless indicated otherwise in a credit line to the material. If material is not included in the article's Creative Commons license and your intended use is not permitted by statutory regulation or exceeds the permitted use, you will need to obtain permission directly from the copyright holder. To view a copy of this license, visit http://creativecommons. org/licenses/by/4.0/.

(c) The Author(s) 2021

\section{ON BEHALF OF THE PEDIATRIC POLICY COUNCIL}

Shetal Shah ${ }^{3}$, Jean L. Raphael ${ }^{4}$, Mona Patel ${ }^{5}$, Jonathan Davis ${ }^{6}$, DeWayne Pursley ${ }^{7}$, Tina L. Cheng ${ }^{8}$, Sherin U. Devaskar ${ }^{9}$, Joyce Javier ${ }^{5}$, Lois Lee $^{7}$, Lisa Robinson ${ }^{10}$, Mary Leonard ${ }^{11}$, Shale Wong ${ }^{12}$, Beth Tarini ${ }^{13}$ and Monika Goyal ${ }^{13}$

${ }^{3}$ New York Medical College, Valhalla, NY, USA. ${ }^{4}$ Baylor College of Medicine, Houston, TX, USA. ${ }^{5}$ University of Southern California, Los Angeles, CA, USA. ${ }^{6}$ Tufts Medical Center, Boston, MA, USA. ${ }^{7}$ Harvard Medical School, Boston, MA, USA. ${ }^{8}$ University of Cincinnati College of Medicine, Cincinnati, OH, USA. ${ }^{9}$ University of California Los Angeles, Los Angeles, CA, USA. ${ }^{10}$ University of Toronto Temerty Faculty of Medicine, Toronto, ON, Canada. ${ }^{11}$ Stanford University School of Medicine, Stanford, CA, USA. ${ }^{12}$ University of Colorado School of Medicine, Aurora, CO, USA. ${ }^{13}$ George Washington University School of Medicine and Health Sciences, Washington, DC, USA. 